\title{
Strength analysis of the lightweight-designed power battery boxes in electric vehicle
}

\author{
Yuhang $\mathrm{An}^{\# 1}$, Xishu $\mathrm{Wang}^{\# 1}$, Nannan Dou $^{\# 1}$, and Zhengbin $\mathrm{Wu}^{* 1}$ \\ ${ }^{1}$ Tianjin Chinese Academy of Sciences Institute of Advanced Technology, No.3 Haitai-Development \\ Six Road, Xiqing District, Tianjin, PR China \\ ${ }^{\#}$ These authors contributed equally to this work.
}

\begin{abstract}
The weight lightening of electric vehicles' power battery box not only improves the vehicles' mileage but also extends the service life of the power battery, while in practice the design of lightweight shall not sacrifice its strength for safety reason. Herein, three materials including the glass fiber composite, carbon fiber composite, and metal steel are used to develop the same power battery box and their strengths are simulated. The results show that the sheet molding compound (SMC, a kind of glass fiber composite) power battery pack shall be damaged when the loaded extrusion force is increased to $98.2 \mathrm{kN}$; for the metal power battery pack, a force of $81 \mathrm{kN}$ would make the deformation more than $30 \%$; while for the carbon fiber composite one, it can stand the extrusion test up to $100 \mathrm{kN}$, and the specific gravity and specific strength are higher than the former two materials under the same design model condition. This study proves the carbon fiber composite has the advantages of high strength and light weight when applied to the power battery box.
\end{abstract}

Keywords: Carbon fiber composites; Simulation analysis; Power battery box; Lightweight; Specific strength.

\section{Introduction}

With the rapid growth of the number of vehicles during the last decade, new energy vehicles are emerging as the next generation transportation to alleviate the strong dependence of the automobile industry on fossil oils and to reduce pollutant emissions. The development of new energy electric cars, as a strategic developing sector, shall thus optimize the energy structure and protect the natural environment, which is critical to the overall as well as long-term social and economic development.[1] As one of the core technologies of new energy electric vehicles, power battery box has exerted great influence on the car's performance. The pursuit of lightweight power battery box is urgently needed before the substantial scientific advances in batteries, motors, electronic controls, etc.[2]

According to previous studies, it is highly probable to find a high-strength, light-weight, and low-cost box material for an electric car power battery.[3] In particular, the lightweight design of power battery box materials needs not only to reduce the weight, but also to fulfill the necessary criteria of vehicle strength and safety. For example, the ultra-light concept

* Corresponding author: zb.wu@siat.ac.cn 
automobile was created by General Motors in the United States as early as 1992. The car's body was made of carbon fiber composite materials and weighed $191 \mathrm{~kg}$ in total.[4] Sunarto Kaleg et al.[5] improved the design based on the optimized material thickness and achieved the highest quality battery case by using 5052-0 series aluminium alloy as the battery materials. Despite the fact that significant progresses have been accomplished in this field, few studies were performed in regard to lightweight materials comparison for power battery packs under extrusion conditions. A detailed analysis would be helpful and in return advance this field.

In this work, the most used materials including sheet molding compound (SMC, a kind of glass fiber composite), carbon fiber reinforced plastics (CFRP), and metal are selected and modelled to study the effect of extrusion force. To simplify some non-structural parts in power battery packs, 3D modelling software and finite element pre-processing software are applied to mesh the power battery pack of electric vehicles. The properties of materials and boundary conditions of the simulated battery pack are created based on the actual situation.[6] Based on simulation results, the strength of battery packs made of three materials are compared under the same standard operating conditions, and the optimal option for lightweight power battery packs is thereafter obtained.

\section{Materials and experiments}

\subsection{Materials and modelling}

This study is based on a company's mini pure electric car, which has met legal criteria but needs further modification to lower energy consumption due to the overweighted power battery box. To achieve this, the lightweight materials of power battery boxes, i.e., glass fiber reinforced plastics (GFRP) composed of thermosetting material sheet molding compound (SMC), carbon fiber reinforced plastics (CFRP), and metal material Q235 steel are chosen as the research objects in this study. Notably, SMC is chosen since it is primarily used in the molding industry as a prepreg of GFRP.[7] It is also widely utilized in automobile body panels, high-strength electrical components, and numerous structural sections. In term of strength, elastic isotropic model with strength criterion on maximum equivalent stresses is chosen and shall be enough for evaluation.

The parameters for each material are set as following. (1) For SMC material, data obtained from actual static compression tests and other similar studies by authors are used as model parameters and ultimate stress, as listed in Table 1. (2) For CFRP material, it is designed to be made up of epoxy resin (or other resins) and carbon fiber according to conventions. Carbon prepreg's strength is directional because of the anisotropic nature of carbon fiber. The mixture of twill cloth and unidirectional fiber is created to suit the strength criteria. Parameters for woven and unidirectional monolayers, obtained from experiments, are presented in Table 2. A bilinear isotropic plastic hardening model with elastic material is used in simulation. (3) For Q235 steel material, wide-accepted characteristics are employed, as shown in Table 3.

In line with the aim of this study and the actual situation of the structure, the preprocessing software are used to simplify and mesh the battery pack structure, and the finite element model of the battery pack are established. The finite element model of the battery pack is dominated by quadrilateral shell elements, supplemented by a small amount of triangle elements, and extrusion cylinder is set as a solid element. 
Table 1. Physical and mechanical properties of SMC composite.

\begin{tabular}{|c|c|c|c|c|}
\hline Parameter & $\begin{array}{c}\text { Density } \\
(\mathbf{k g} / \mathbf{m 3})\end{array}$ & $\mathbf{E}(\mathbf{G P a})$ & $\begin{array}{c}\text { Poisson's } \\
\text { ratio } \boldsymbol{\mu}\end{array}$ & бcrit (MPa) \\
\hline SMC & 2251 & 12.5 & 0.3 & 120 \\
\hline
\end{tabular}

Table 2. Physical and mechanical properties of CFRP materials.

\begin{tabular}{|c|c|c|}
\hline Parameter & Woven fabric & Unidirectional tape T700 \\
\hline $\mathbf{E 1}(\mathbf{G P a})$ & 159.520 & 245 \\
\hline $\mathbf{E 2}(\mathbf{G P a})$ & 11.660 & 6.9 \\
\hline $\mathbf{G 1 2}(\mathbf{G P a})$ & 3.813 & 3.9 \\
\hline $\mathbf{G 1 3}(\mathbf{G P a})$ & 3.813 & 3.9 \\
\hline $\mathbf{G 2 3}(\mathbf{G P a})$ & 3.961 & 3.0 \\
\hline $\boldsymbol{\mu 1 2}$ & 0.267 & 0.87 \\
\hline $\boldsymbol{\sigma B} 1+(\mathbf{M P a})$ & 2005 & 2160 \\
\hline $\boldsymbol{\sigma B 2}+(\mathbf{M P a})$ & 68 & 45 \\
\hline $\boldsymbol{\sigma B} 1 \boldsymbol{-}(\mathbf{M P a})$ & 1355 & 980 \\
\hline $\boldsymbol{\sigma B} 2-(\mathbf{M P a})$ & 198 & 83 \\
\hline $\begin{array}{l}\text { Interlaminar shear } \\
\text { strength } \boldsymbol{\tau 1 3}(\mathbf{M P a})\end{array}$ & 60 & 0.3 \\
\hline Monolayer thickness $(\mathbf{m m})$ & 0.3 & \\
\hline
\end{tabular}

Table 3. Physical and mechanical properties of Q235.

\begin{tabular}{|c|c|c|c|c|c|}
\hline Parameter & $\begin{array}{c}\text { Density } \\
(\mathbf{k g} / \mathbf{m 3})\end{array}$ & $\begin{array}{c}\text { Yield stress } \\
\boldsymbol{\sigma T}(\mathbf{M P a})\end{array}$ & $\begin{array}{c}\text { Ultimate stress } \\
\boldsymbol{\sigma B}(\mathbf{M P a})\end{array}$ & $\begin{array}{c}\text { Poisson's } \\
\text { ratio } \boldsymbol{\mu}\end{array}$ & $\begin{array}{c}\text { Young } \\
\text { modulus E } \\
(\mathbf{G P a})\end{array}$ \\
\hline $\mathrm{Q} 235$ & 7.85 & 235 & 400 & 0.3 & 200 \\
\hline
\end{tabular}

\subsection{Extrusion experiment design}

The experiments in this study are carried out following the condition and programme requirements of the Chinese national standard "GB/T 38031-2020 safety requirements standard for power battery for electric car" for power battery box, as listed below in details.

1) The radius of the extrusion cylinder shall be $75 \mathrm{~mm}$, and the height of it shall be more than the test object but no more than $1 \mathrm{~m}$.

2) The extrusions shall be carried out along $X$ and $Y$ direction, which represent the driving direction of the vehicle and the perpendicular direction of the driving direction in the horizontal plane, respectively.

3) When the extrusion force exceeds $100 \mathrm{kN}$ or the extrusion distortion reaches $30 \%$ along the extrusion direction, the extrusion shall be stopped.

4) The extrusion speed shall be no more than $2 \mathrm{~mm} / \mathrm{s}$. 


\section{Results and discussion}

\subsection{Structural design and strength calculation analysis of SMC power battery box}

In simulation, a model of elastic isotropic material with strength criteria based on maximum equivalent stress and parameters from Table 1 is used. When equivalent stress reaches ultimate value, it is removed, and then the redistribution of stress occurs. Fig. 1(a) and (b) shows stress-strain state of a battery pack box parts made of SMC during fracture.

At the same time, the model allows estimation of damage evolution in composite and its influence on bearing capacity. Parts of the box are connected and have contact interaction with experimental tool's cylinders. Boundary conditions were changed for the definition of a bearing capacity. Displacement of one of the cylinders is limited at all degrees of freedom, while the second cylinder can only be displaced along the battery pack box on a distance corresponding to maximum permissible compression. In such conditions, the maximum stress results in bearing capacity failure and is equal to $\mathrm{F}_{\mathrm{SMC}}=98.2 \mathrm{kN}$.

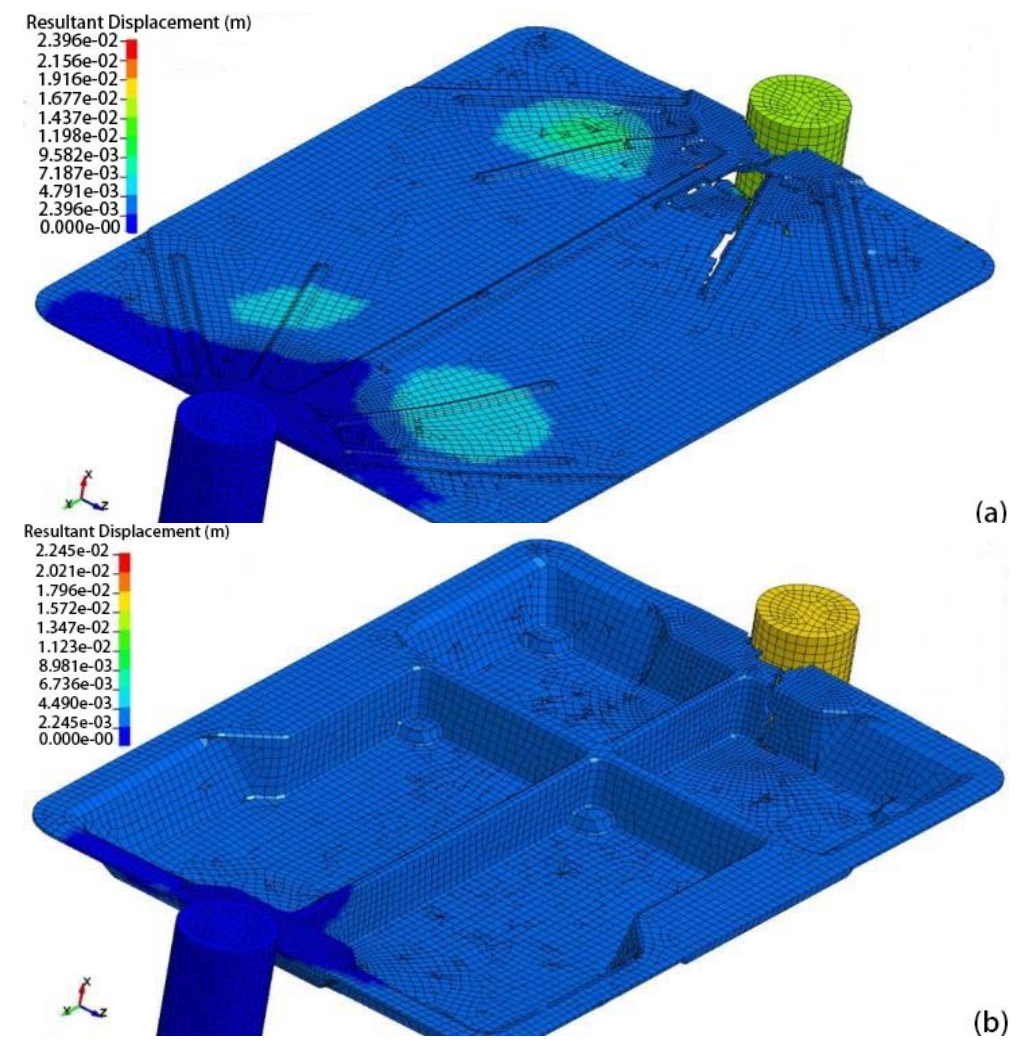

Fig. 1. Displacement analysis of SMC power battery box during fracture. (a) Upper part, (b) Lower part. 


\subsection{Structural design and strength calculation analysis of CFRP power battery box}

Similar to power battery box made of SMC, a design of a battery pack box with maximum bearing capacity was developed with the employment of high anisotropic material - CFRP. In this study, carbon fabric consists of woven and unidirectional layers. A model of a multilayered composite material in quasi-static setting is used within the borders of a plane stress state.

A finite element model of a composite box was calculated. Building of a geometrical model with given parameters occurs in "Geometry" module. Parameters of braided monolayer and unidirectional monolayer obtained in laboratory are shown in Table 2. Fig. 2(a) illustrates the visualization of zones thickness in accordance with complex layup scheme. Surfaces are divided into many fabric and unidirectional tape layup zones for maximum bearing capacity. Fig. 2(b) shows CFRP box deformation in axial direction. According to the extrusion test method, the carbon fiber composite power battery box does not produce damage until the maximum force reaches $F_{\mathrm{CFRP}}=115.6 \mathrm{kN}$.
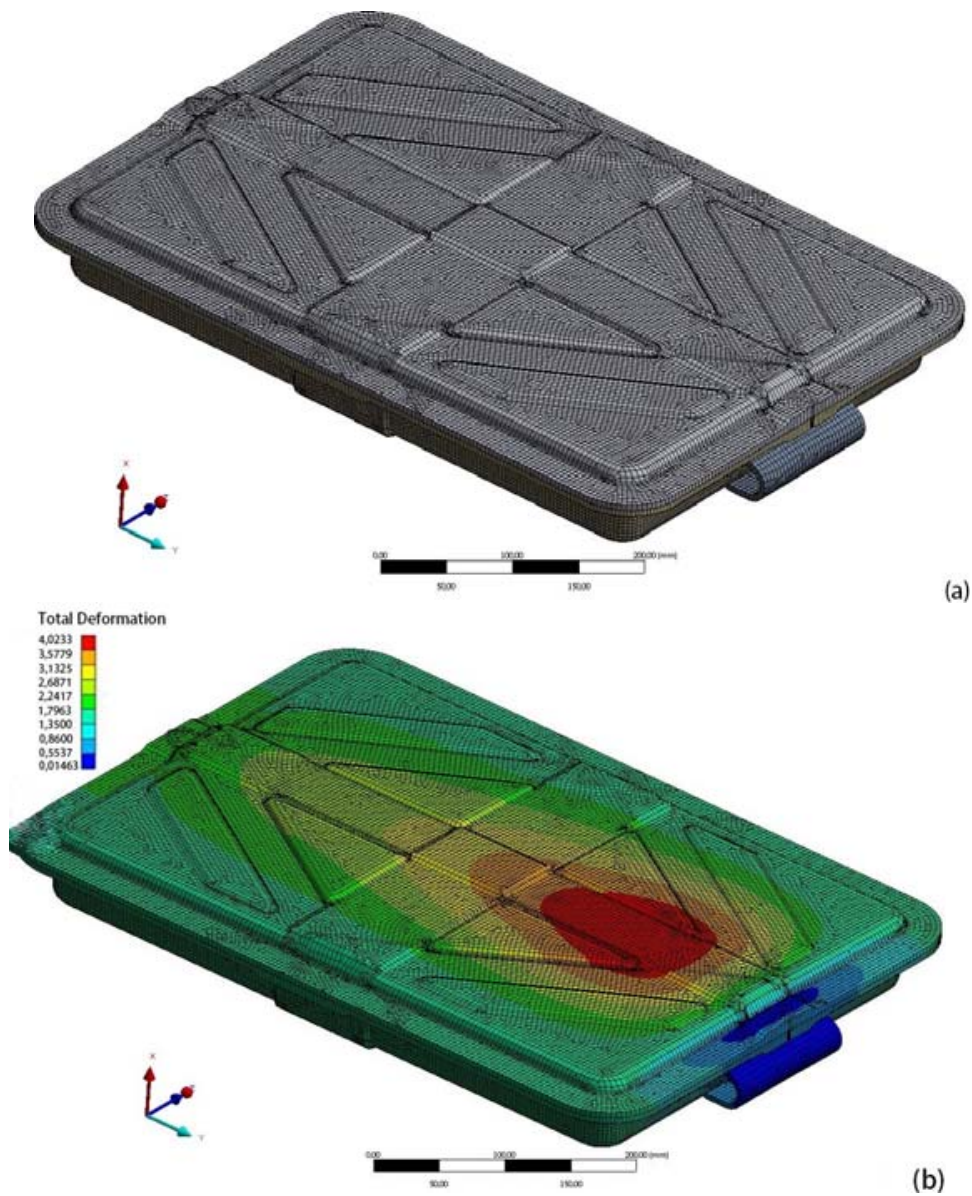

Fig. 2. Analysis of CFRP power battery box. (a) Finite element model, (b) Box deformation in axial direction. 


\subsection{Structural design and strength calculation analysis of metal power battery box}

The Q235 steel is employed in the design of steel power battery boxes and its dynamic strength is simulated. Fig. 3(a) and (b) depict cloud diagrams of plastic strain distribution. It is seen that there is a substantial plastic strain in the steel power battery box when the cylinder of the experimental tool is hidden, but the stress level is lower than the maximum strength. The maximum transverse compression is about $30 \%$ when the maximum extrusion force reaches $\mathrm{F}_{\mathrm{Q} 235}=81.0 \mathrm{kN}$.

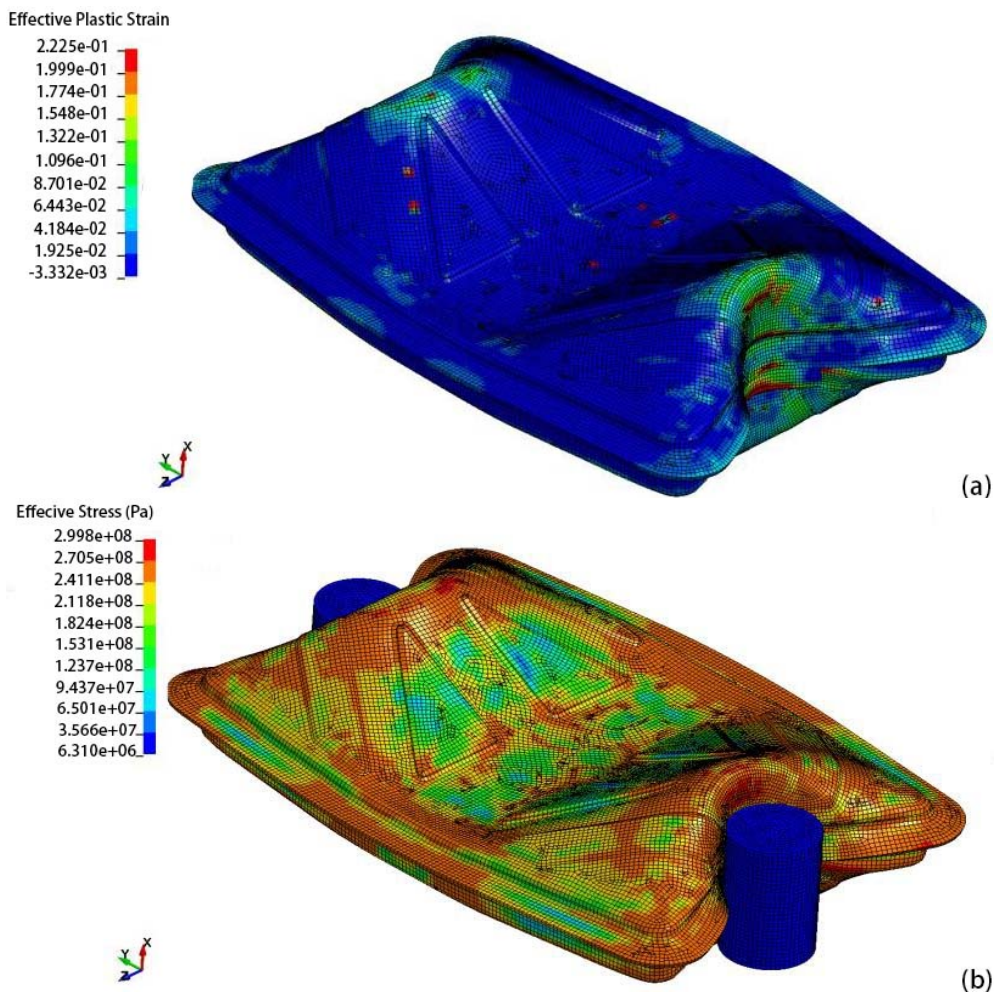

Fig. 3. Analysis of steel power battery box. (a) Effective plastic strain, (b) Effective stress.

\subsection{Comparison of structural design results of power battery box of different materials}

Table 4 tabulates figures of merit for power battery boxes made of various materials, as analysed above. The simulations reveal that the CFRP power battery box has the maximum specific strength, while the steel power battery box has the lowest. Remarkably, the specific strength of CFRP power battery box is 2.58 times that of steel one.

In order to conduct a more precise comparison of characteristics of power battery box made of different materials, a specific parameter is introduced. For estimations of strength, a maximum load $\mathrm{F}$ that leads to the loss of a bearing capacity during axial compression is defined from simulation experiments. A specific strength is defined as the ratio of maximum load to power battery box mass, i.e., 


$$
\sigma=\frac{F}{M}
$$

Specific strength allows preliminary evaluation of strength efficiency of a whole class of promising designs without engineering calculations.

Table 4. Physical and mechanical properties of Q235.

\begin{tabular}{|c|c|c|c|}
\hline Material & $\begin{array}{c}\text { Weight } \\
\text { (g) }\end{array}$ & $\begin{array}{c}\text { Maximum- } \\
\text { loaded force } \\
\text { (kN) }\end{array}$ & $\begin{array}{c}\text { Specific } \\
\text { strength, } \boldsymbol{\sigma}\end{array}$ \\
\hline SMC & 9110 & 98.2 & 10.7 \\
\hline Metal & 10470 & 81.2 & 7.7 \\
\hline $\begin{array}{c}\text { CFRP - } \\
\text { Tape+Fabric }\end{array}$ & 5784 & 115.6 & 19.9 \\
\hline
\end{tabular}

\section{Conclusion}

In summary, three different types of materials including SMC, CFRP, and metal were used to design power battery box in electric vehicles, and their performance are assessed according to simulations. The extrusion simulation showed that to meet the strength requirements of related electric vehicle power battery boxes, the layer-structured CFRP material with unidirectional belt and fabric had the most significant weight reduction effect, followed by GFRP and then metal materials. Compared with the metal-made power battery box, the CFRP material battery pack could reduce the weight by $44.7 \%$, while enhance the specific strength by $158.4 \%$. This study enriches the current theoretical research of the power battery box, and offers more opportunities and effective ways to guide the further lightweight design of the new energy electric vehicles in the aim of meeting the requirements of related extrusion processes.

\section{Acknowledgement}

This work is supported by Tianjin "The Belt and Road Initiative" technical R \& D cooperation and industrialization projects (19YDYGHZ00070).

\section{References}

1. S. Chen, Y. Feng, C. Lin, Z. Liao, Mei, X. Math. Probl. Eng. 2021, 6613602 (2021)

2. H. Zhou, W. Feng, L. Sun, J. Asian Elect.Vehicles 2(1), 531-534 (2009)

3. M. Hartmann, M. Roschitz, Z. Khalil, Mater. Sci. Forum 765, 5 (2013)

4. H. Fuchs, USA: 2007 SPE Automstive Composites Conference, 2-17 (2008)

5. S. Kaleg, Amin, 2016 International Conference on Sustainable Energy Engineering and Application (ICSEEA), pp. 1-5, doi: 10.1109/ICSEEA.2016.7873558 (2016)

6. X. Chen, X. Sun, P. Chen, B. Wang, Y. Zhao, Compos. Struct. 256, 113120 (2020)

7. V. Feuillade, A. Bergeret, J.C. Quantin, A. Crespy, Compos. Sci. Tech. 66(1), 115-127 (2006) 